\title{
Reflexiones sobre la realidad, las nuevas generaciones y las redes sociales, como problemáticas de la enseñanza en tiempos de cuarentena
} Reflections on Reality, New Generations and Social Networks as Teaching Problems in Times of Quarantine

\author{
Jorge Luis Fabian \\ Universidad del Salvador, Argentina \\ jorge.fabian@usal.edu.ar
}

Argentina comenzó el 2020 con un nuevo gobierno que tenía como objetivo principal abocarse a las cuestiones económicas. Sin embargo, este año quedará marcado por las incertidumbres, los desafíos, el establecimiento de nuevas prioridades y el quiebre en las relaciones sociales como las conocíamos hasta ahora.

La educación no es ajena a esta situación y, a diferencia de los países del hemisferio norte, las clases, de la forma en que las concebíamos hasta hoy, ni siquiera comenzaron en Argentina. El pasado 2 de marzo empezó un nuevo ciclo lectivo, pero dos semanas más tarde el Ministerio de Educación, en consonancia con lo establecido por el Poder Ejecutivo, tomó la decisión de suspender "el dictado de clases presenciales en los niveles inicial, primario, secundario en todas sus modalidades, e institutos de educación superior, por catorce (14) días corridos a partir del 16 de marzo".

Esas dos semanas iniciales se han convertido en tres meses en los que las aulas se encuentran vacías, sin saber cuándo volverán a estar ocupadas por docentes y estudiantes. Además, es importante destacar que el ciclo lectivo anterior terminó formalmente el 18 de diciembre de 2019, por lo cual los alumnos están lejos de su ámbito educativo tradicional desde hace seis meses. 
Aunque no siempre lo recordamos, una situación similar, pero de menor duración que la actual, se produjo en junio de 2009, cuando en la Argentina se suspendieron las clases debido a la aparición de la gripe A (H1N1), lo cual generó una fuerte incertidumbre, desde el punto de vista de la continuidad educativa. ${ }^{1}$

Muy pocos colegios contaban con un campus virtual donde subir tareas y el acceso a Internet era muy limitado. La solución en aquel entonces fue enviar a los padres, por correo electrónico, la tarea que deberían realizar sus hijos, ya que muchos, al no tener Internet en su casa, descargaban e imprimían los ejercicios en sus trabajos o concurrían a "locutorios" (cibercafés). Además, muchos docentes armaron cuadernillos con textos y guías de preguntas que dejaban en librerías para que sus alumnos pudieran continuar estudiando hasta que se reanudasen las clases.

En esta nueva realidad, la virtualidad parece ser la mágica solución a la problemática educativa, ya que dictar clases sincrónicas a través de Zoom, Google Meet o Jitsi equivaldría, hipotéticamente, a la presencialidad. Sin entrar en cuestiones de índole pedagógico, cabe plantearse si materialmente esto es posible en una realidad argentina sumamente heterogénea, en la que se incorporan cuestiones que involucran tanto a los alumnos que concurren a escuelas privadas como a los que asisten a establecimientos públicos.

Los últimos informes obtenidos a partir de las pruebas Aprender 2018 muestran que de los estudiantes del último año del nivel primario en la Ciudad Autónoma de Buenos Aires (CABA) únicamente $7.2 \%$ no tiene acceso a internet; sin embargo, en otras partes del país esa cifra asciende a 40.7\%. Además, tener Internet no equivale a poder participar de clases sincrónicas, ya que se necesita, como mínimo, que el estudiante tenga acceso a una computadora y a banda ancha de más de $20 \mathrm{Mbps}$. La aclaración de que se necesita "una computadora" se refiere a que, durante la cuarentena, muchos padres debieron trabajar desde sus casas y, en líneas generales, en el mismo horario en el que funciona la escuela, por lo que un solo dispositivo por grupo familiar tampoco alcanza. Hay que sumar a esta

\footnotetext{
${ }^{1}$ Las clases fueron oficialmente suspendidas a partir del 1 de julio hasta el 10 de agosto. Sin embargo, muchos colegios privados ya lo habían hecho a principios de junio ante la aparición de los primeros casos.
} 
cuestión que los más chicos deben estar acompañados de sus padres durante la clase sincrónica, en caso de tenerla, y luego ayudarlos a realizar las actividades propuestas por los docentes.

Más allá de estas dificultades debemos preguntarnos si ésta es la única forma de mantener la continuidad pedagógica. Quizás lo que no nos estamos planteando es si esta modalidad es la que prefieren nuestros estudiantes o si es la que prefieren los docentes. Porque, en definitiva, cuál es la diferencia entre una clase por Zoom, Google Meet o Jitsi y una en el aula. ¿Será una nueva forma de sostener a la escuela de la modernidad en la posmodernidad?

Hoy nos encontramos frente a la denominada Generación Z, que abarca al grupo poblacional cuyo nacimiento se produce después de 1995 y que posee como referencia temporal el cambio de milenio. Sus miembros han nacido en una era totalmente digital y en el contexto consolidado de la globalización. Ellos cuentan con nuevas expectativas vinculadas a su inserción en la vida profesional y con habilidades específicas relacionadas con la adaptación a los diferentes contextos y al uso de la tecnología. La Generación Z también se caracteriza por haber desarrollado desde muy temprana edad el multitasking, a partir de la gran cantidad de información que obtienen de las redes sociales y de otras plataformas.

Asimismo, algunos autores denominan a estos jóvenes como representantes de la Generación\#, ya que poseen la capacidad de estar conectados de manera especializada o segmentaria, y de forma deslocalizada y móvil, a una o varias herramientas de la web social con características etarias, sociales y culturales propias. Twitter e Instagram son ejemplos claros de esta conectividad segmentaria. Nuestros estudiantes viven conectados a la realidad de una manera particular a partir de su Smartphone, lo cual ha generado una nueva concepción del tiempo que se caracteriza por ser "viral", porque las informaciones que circulan por las redes sociales no se expanden de forma secuencial, sino viral, multiplicándose de forma exponencial, de manera rápida y en oleadas, como los virus epidémicos y los cibernéticos.

Es por todo esto que, al pensar nuevas estrategias didácticas en estos tiempos de pandemia y cuarentena, debemos tener en consideración que nuestros estudiantes se están educando plenamente en 
una era digital, donde la tecnología y las redes sociales son parte de sus vidas $y$, por tanto, esto produce un mundo de vida adolescente en el que la comunicación móvil es insoslayable, omnipresente y crucial como forma de existencia social, visibilidad y afirmación identitaria. Por ello, el modelo de clase sincrónica parecería no ser el más apropiado según las características que lo definen.

Si bien las instituciones trabajan con planificaciones y armados de proyectos de mediano o largo plazo, a veces los alumnos generan "imprevistos" que cumplen una función disruptiva provocando la necesidad repensar la actividad áulica. Éstos descolocan al docente y ponen a prueba su capacidad de adaptación, ya que éste debe pensar y armar, en tiempo récord, un proyecto que tenga en consideración la demanda de los alumnos, los lineamientos de la escuela y que se corresponda con el diseño curricular y las normativas vigentes.

En 2019, un grupo de alumnas de cuarto año del nivel secundario de un colegio de la provincia de Buenos Aires fue a hablar con la directora de la institución, porque no se estaba abordando la problemática de la violencia de género en la escuela y, como en dos días se realizaría la quinta marcha \#NiUnaMenos, ellas querían realizar una reflexión al respecto. Ella las felicitó por la iniciativa, les brindó su apoyo y les solicitó que eligieran un docente para trabajar.

Las alumnas eligieron al profesor de historia, quien orientó a las estudiantes en el armado de la reflexión y les propuso que realizaran una breve reseña histórica de las luchas del movimiento feminista en Argentina.

Paralelamente, en la asignatura de geografía, la docente se encontraba trabajando las problemáticas medioambientales a partir de la necesidad de tomar conciencia del fenómeno del cambio climático ocasionado por la contaminación, y como parte de las actividades se utilizó el ejemplo de Greta Thumberg, la joven activista sueca que lucha por el cuidado del medioambiente y que se destaca por su fuerte impacto en las redes sociales. Su cuenta de Instagram suma, en la actualidad, 7.7 millones de seguidores.

El análisis de la obra de la joven activista generó una fuerte convicción sobre la importancia de visibilizar las problemáticas que preocupaban a su generación. Debido a esto, las alumnas se plantearon la posibilidad de crear un espacio en las redes sociales que visibi- 
lizara a las distintas mujeres cuyos aportes al movimiento feminista, al desarrollo social, científico y cultural de la sociedad argentina hubieran sido relegados con el transcurso del tiempo.

Con la colaboración del profesor de historia decidieron crear una cuenta de Instagram para mostrar el trabajo de investigación que venían haciendo. Esta red social fue elegida por las alumnas porque les permitía usar imágenes e incluir texto, y además porque es la que ellas usan permanentemente. Así surgió @mujeres.historicas, la cuenta que tiene por objeto "visibilizar a las mujeres que han sido invisibilizadas", y se adoptó la imagen de Victoria Ocampo como foto de perfil. Las publicaciones se programaron de manera diaria y se estableció que las siete publicaciones iniciales correspondieran con las primeras siete egresadas de la Universidad de Buenos Aires (UBA). Lo interesante es que poco a poco sus compañeros se fueron sumando al proyecto hasta hacerlo de todos los alumnos de cuarto año. ${ }^{2}$

Es cierto que @mujeres.históricas surgió en 2019, cuando no había pandemia ni cuarentena, pero este proyecto provocó que el docente comprendiera que las formas de pensar de los alumnos no eran las suyas y que debía buscar otras maneras de comunicarse con sus estudiantes. En primer término, se comenzó a generar un intercambio por Instagram con las alumnas que manejaban la cuenta, quienes le consultaban sobre cuestiones de contenido ya que, presencialmente, sólo tenían contacto con él los martes de 9:30 a 11:30 hrs. Al comenzar la cuarentena, el docente decidió crear con el ahora quinto año un grupo de Instagram para comunicarse con el curso: 5toCDN.

Aunque el colegio posee un campus virtual donde los docentes suben actividades y notificaciones para los alumnos, éste les resulta totalmente ajeno, entre otras cosas, por la rigidez de su formato y por la falta de inmediatez en la comunicación. Debido a esto, el docente decidió que, además de utilizar el campus virtual, realizaría

\footnotetext{
${ }^{2} \mathrm{Al} 18$ de mayo de 2020 la cuenta de Instagram de @mujeres.historicas tiene 2974 seguidores. Además poseen una página de internet https://menlahistoria.wixsite.com/blog/ inicio/, una playlist en Spotify https://open.spotify.com/playlist/2MwmjRdo8AkJpVfe8Kc7a Q?si=WW3rlEH3QDmwPpyjJ1hZfg y una página en Facebook https://www.facebook.com/ mujeres.historica/
} 
todas las comunicaciones respecto a los trabajos que deben realizar sus estudiantes por el grupo de Instagram. De hecho, los horarios en los que se realizarán las clases por Google Meet también son consensuados por ese medio, antes de ser informados formalmente por el campus, con el objetivo de que no haya superposición de horarios con las otras materias.

Como mencionamos en un principio, el hecho de que hace cinco meses que los estudiantes no asistan al colegio provoca que éstos pierdan sus hábitos de estudio, y que sus horarios sean diferentes a aquellos que los adultos entenderíamos como "normales". Hace unas semanas, al finalizar la clase sincrónica de historia, el docente les dio una tarea que debían subir al campus para el próximo martes. Ese jueves a las 21:50 hrs., aproximadamente, una alumna le envió un mensaje de audio por Instagram porque tenía una duda sobre el trabajo. La primera reacción no fue positiva, pero luego de escuchar la consulta, el docente la respondió en tres audios (recordemos que la duración de los audios de Instagram es como máximo de un minuto) a las 22:15 hrs.

Luego de esto le surgió, naturalmente, el primer interrogante: “ ¿cómo es que estoy respondiendo un audio de Instagram a las 22:15 hrs. de la noche?" Al siguiente martes, el docente les dijo que cuando tuvieran una duda le escribieran, o le mandaran un audio, porque entendía que sus tiempos y formas de comunicación eran diferentes de las suyas, y que les respondería por el mismo medio. Como no podía ser de otra manera, el jueves a las 23:00 hrs. recibió un mensaje que empezaba "Buenas noches, profe. Disculpe la hora, pero si no dsp me olvido". A la alumna le había interesado el tema de la clase del martes y había estado buscando información y escuchando podcasts, y quería saber si algo que había encontrado era verdad, porque le había impactado mucho. La respuesta del docente fue el viernes a las 10:00 hrs. y el agradecimiento de la alumna a las 11:14 hrs.

También existe 6toCDN, que está integrado por los estudiantes del último año, a quienes el profesor de historia conoce desde que éstos estaban en cuarto, y de los que, actualmente, es profesor de metodología y técnicas de investigación, cuya interacción es aún mayor y el lenguaje que se utiliza en el grupo es mucho más coloquial. Debido a que junto al profesor participaron durante los 
últimos años en distintas competencias que se llevaron a cabo fuera del colegio, y además porque el docente hace dos años apenas usaba Instagram, tiene con ellos grupos de WhatsApp como por ejemplo el G20, que fue creado cuando participaron del "G20. Simulación estudiantil. Experiencia educativa de consenso", que se hizo en la Argentina en 2018, o el Parlasur, que surgió a partir de la participación de los estudiantes en 2019 en el "Parlamento Juvenil del Mercosur". Ambos siguen activos y más en tiempos de cuarentena, cuando la necesidad de comunicarse e interactuar, aunque sea a propósito de temas históricos, es muy importante para los jóvenes.

Retomando el proyecto de @mujeres.historicas, el profesor de historia decidió utilizarlo en esta cuarentena para que los alumnos buscaran información sobre diferentes mujeres, para ir "posteándola" en forma de efemérides, y utilizar este recurso como disparador para trabajar distintos temas. A modo de ejemplo, podemos mencionar las publicaciones del 24 de marzo (día por la memoria, la verdad y la justicia) sobre las "Madres de Plaza de Mayo"; del 2 de abril (día del veterano y de los caídos en la Guerra de Malvinas), donde subieron una foto de un grupo de enfermeras que participaron en la guerra y de las que poco se sabe; del 24 de abril, sobre Juana Manso, ese día se recordaron los 145 años de su fallecimiento, y el 18 de mayo, día de la escarapela, sobre el rol de las mujeres como promotoras de su uso.

La pandemia y la consiguiente cuarentena nos obligan a reflexionar sobre nuestras prácticas educativas cotidianas. Hoy la cuestión no se centra en el armado de las clases virtuales como forma de transformar las clases presenciales hasta que pueda volver a darlas cara a cara, sino en problematizar sobre otras cuestiones que pasan en la escuela. La comunicación entre el docente y el alumno, y la necesidad de la generación de empatía es fundamental en el contexto en el que vivimos y que hoy se ha visibilizado por la pandemia.

El profesor de historia siempre recuerda cuando sostenía que era totalmente negativo aceptar a los estudiantes como amigos en Facebook porque esto era invasivo, y ellos conocerían su vida personal, lo cual no era apropiado para la relación docente-alumno, porque se podía perder el respeto. Por supuesto que esto no era la opinión de un único docente, sino que existía, y quizás aún existe, un consenso sobre la "distancia" que debe existir para seguir mante- 
niendo la relación asimétrica que nos ha propuesto la escuela de la modernidad.

A su vez, el desconocimiento que poseen muchas veces los maestros sobre cómo funcionan las redes sociales y las posibilidades que éstas ofrecen para la actividad docente, que trasciende la mera impartición de contenidos, generan temor y rechazo. Aunque los docentes han sido educados en un mundo analógico, deben tomar conciencia de que sus estudiantes pertenecen a uno digital. Esto implica que sus concepciones espaciotemporales son diferentes, y que debe buscar la manera de comprender su cosmovisión del mundo. Esto no implica que la comparta.

Retomando el caso del profesor de historia, su elección como referente para canalizar sus inquietudes y la confianza para interactuar en los respectivos grupos de Instagram o WhatsApp requiere nunca olvidarse de qué rol cumple cada uno. No se está queriendo hablar de la vieja asimetría en la relación docente-alumno, sino de la necesidad de establecer nuevas formas de llevar adelante el proceso educativo, entendiendo que ambos son personas, reinterpretando la vinculación entre ellos y fortaleciendo la empatía.

Los estudiantes necesitan confiar en el docente y, lo más difícil, el docente debe confiar en ellos. Que interactúen en las redes sociales no significa que los estudiantes no tengan que estudiar, o que el docente no tenga que educar, pero sí conlleva una mayor responsabilidad para este último, ya que éste es ejemplo y guía. Igualmente, es necesario comprender que la problemática comunicacional entre ambas partes es un inconveniente que la educación viene arrastrando desde hace tiempo, y que la pandemia simplemente visibilizó aún más.

Nadie duda de que esta crisis sanitaria nos dejará mucho para pensar y reflexionar. Seguramente el profesor de historia deberá replantearse muchas cosas, por ejemplo, por qué considera que, debido a que no conoció de forma presencial a sus alumnos de cuarto año y no interactuó con ellos "cara a cara", no se anima a formar el grupo de Instagram de 4toCDN. 